\title{
Sensory properties of iodine-biofortified potatoes
}

\author{
Maria Piochia $^{\text {**, }}$ Emma Chiavaro ${ }^{b}$, Angelo Cichellic, Luisa Torri $^{\mathrm{a}}{ }^{\text {, Lorenzo Cerretani }}{ }^{\mathrm{d}}$ \\ ${ }^{a}$ University of Gastronomic Sciences, Piazza Vittorio Emanuele, Bra (CN), Italy; ${ }^{b}$ Department of Food and Drug, University \\ of Parma, Parma, Italy; 'Department of Medical, Oral and Biotechnological Science, University "G. d'Annunzio" of Chieti- \\ Pescara, Chieti Scalo (CH), Italy; ${ }^{d}$ S.A.L.P.A. Roseto, Roseto degli Abruzzi, Teramo (TE), Italy
}

*Corresponding Author: Maria Piochi, University of Gastronomic Sciences, Piazza Vittorio Emanuele, Bra (CN), Italy. Email: m.piochi@unisg.it

Received: 28 August 2020; Accepted: 12 December 2020; Published: 01 February 2021

(c) 2021 Codon Publications

OPEN ACCESS (c) (i) (2) (2)

PAPER

\begin{abstract}
The present study assessed the sensory impact of potatoes biofortification with iodine and the stability of iodine during six months of storage. Four biofortified cultivars (Cupido, Marabel, Orchestra and Universa) and their controls (non-biofortified) were evaluated. Descriptive analysis was applied with a panel to describe the sensory properties, and triangle tests were applied with consumers to evaluate perceivable differences between controls and respective biofortified samples at the end of shelf life. Iodine content was quantified on raw potatoes for three periods of storage. Descriptive analysis showed some differences between controls and iodine-biofortified samples, especially in texture (hardness). However, consumers did not significantly discriminate fortified from unfortified samples. Iodine was stable during storage in all varieties. Orchestra cultivar showed the highest iodine content, while Universa the lowest.
\end{abstract}

Keywords: biofortification, descriptive analysis, essential micronutrient, functional food, potato, triangle test

\section{Introduction}

Iodine is an essential micronutrient consumed with diet, and is necessary for the biosynthesis of thyroid hormones which regulate metabolic functions (Trumpff et al., 2013). The daily recommended iodine intake ranges from 90 to $250 \mu \mathrm{g}$, depending on several factors, among others, age and physiological status (e.g. childhood, adultness, pregnancy/lactation) (Zimmermann et al., 2012). Inadequate iodine intake is currently one of the main micronutrient deficiencies worldwide, leading to a spectrum of clinical and social issues called 'Iodine deficiency disorders' (Gonzali et al., 2017)' and iodine deficiencies still represent a severe problem in certain geographic areas (Khattak et al., 2017). Iodine biofortification in vegetables is a promising strategy to increase iodine intake and overcome iodine deficiencies in human diet. However, the main critical issues in biofortification of iodine vegetables rely on the stability of the mineral during storage and the potential sensory modifications, which can compromise acceptability of fortified food.

There are different strategies to address increase in iodine such as mineral supplementation, food fortification and biofortification of crops (Comandini et al., 2013). Biofortification is applied to increase the bioavailable nutrient content of the edible portion of crop plants (Hotz, 2013). Biofortification of plant foods can be obtained by the following three ways: agronomic biofortification, conventional plant breeding of selected cultivars, and genetic engineering (Carvalho and Vasconcelos, 2013). The aim of the agronomical approach is to increase micronutrients through mineral fertilisers and/or through the improvement of soil mineral elements' mobilisation (Saltzman et al., 2013). Recently, many authors have developed and tested specific agronomical practices to increase iodine content in different vegetables and crops, such as potato and tomato (Caffagni et al., 2011; Zanirato 
and Mayerle, 2009); barley and wheat (Caffagni et al., 2011); spinach and lettuce (Smoleń et al., 2014; Weng et al., 2013); cabbage, coriander, cucumber, eggplant, long cowpea and hot pepper (Weng et al., 2013); carrot and onion (Zanirato and Mayerle, 2009).

As a general rule, food fortification should not alter the stability, colour or flavour of the vehicle food (Dwyer et al., 2015). Iodine salts may theoretically be involved in colour or oxidative reactions, since iodide is a strong reducing agent and iodate is a strong oxidizing agent (Winger et al., 2008). Since the modification of the sensory properties of food can negatively affect consumers' hedonic responses, it is necessary to maintain an adequate level of acceptance when dealing with fortified foods. In fact, in spite of certain consumers that compromise on taste when consuming healthy foods (Verbeke, 2006), often functional foods are characterised by critical sensory properties which are more disliked by consumers compared to conventional foods ( Dal Bello et al., 2017; Torri et al., 2016).

The effect of iodine on food sensory quality has been studied by many authors (Greis et al., 2018; West and Koning, 1995). On biofortified vegetables, particularly considering potatoes, studies were performed regarding the process of biofortification (Caffagni et al., 2011; Zanirato and Mayerle, 2009), the stability of iodine during cooking ( Caffagni et al., 2012; Comandini et al., 2013) and the bioavailability of iodine (Tonacchera et al., 2013).

However, to the present authors' best knowledge, no study has explored the stability of iodine during storage in biofortified potatoes and its effect on sensorial properties.

Therefore, the aim of the present study was two-fold: (1) to evaluate the effects of iodine biofortification on sensory properties by describing the sensory properties of controls and biofortified samples (descriptive analysis $[\mathrm{DA}]$ ) and by verifying whether biofortified cultivars were discriminated from non-fortified controls (triangle test); and (2) to evaluate the chemical stability of iodine in raw biofortified potatoes during storage (iodine analysis). Since prior results showed that iodine is stable during domestic cooking, including baking (Comandini et al., 2013), the analysis of iodine was done directly on raw potatoes to establish the following: (1) the starting natural quantity of iodine in each cultivar; (2) the effect of iodine biofortification on each cultivar immediately after harvesting (storage time at which potatoes are extremely fresh) and (3) stability at the end of six months (storage time corresponding to end of shelf life, the moment at which the potatoes are the least fresh). Sensory analyses were conducted at the end of shelf life (i.e. six months), which was potentially the most critical moment, since the product was not fresh.

\section{Materials and Methods}

\section{Growing and processing of potato cultivars}

Potatoes (Solanum tuberosum) are grown in a limited zone of Emilia-Romagna region in Italy, and these were kindly donated by Pizzoli S.p.A. (Budrio, Italy). Four international cultivars were chosen for the biofortification process: Cupido, Marabel, Orchestra and Universa. These cultivars were chosen because of their maximum usage to produce fresh potatoes for global commercial level. For each cultivar, control and biofortified samples were obtained from the same field of growth to minimise any variability factor other than biofortification process. One batch was analysed for each cultivar. In text, letter ' $\mathrm{C}$ ' is used to identify controls, while letter ' $\mathrm{B}$ ' is used for biofortified samples. In all, eight samples were evaluated (Cupido_C, Marabel_C, Orchestra_C, Universa_C, Cupido_B, Marabel_B, Orchestra_B and Universa_B). Iodized potatoes were obtained by means of a patented agronomic procedure (Zanirato and Mayerle, 2009) through foliar fertilisation realised during the growing season. The harvest was done three weeks after the iodine treatment. Potatoes were stored under conventional industrial storage conditions: in a plastic box put in a warehouse designed for potato storage in absence of light, and in ventilated and conditioned atmosphere at $8^{\circ} \mathrm{C}$ and $80 \%$ of relative humidity during all storage period. No sprout inhibitors were used during storage. A period of six months was chosen as a shelf life, since it is a reasonable/representative storage time for commercial potatoes in controlled conditions before they are packaged and distributed immediately.

\section{Sensory evaluation}

All sensory tests were performed after six months of storage. Participants freely joined the sensory activities and written informed consent was obtained from all participants before inclusion in the tests. The study was in conformity with the Declaration of Helsinki. Prior to sensory evaluations, assessors received both verbal and written instructions regarding the evaluation procedures.

\section{Preparation of samples}

Whole unpeeled potatoes were washed in tap water and cooked for $80 \mathrm{~min}$ in a steam oven (Chef top, Unox S.p.A., Padova) at $100^{\circ} \mathrm{C}$ and $100 \%$ of relative humidity. After cooking, whole potatoes were cooled at a room temperature of $20^{\circ} \mathrm{C}$ for $2 \mathrm{~h}$. Approximately 30 min prior to sensory evaluations, potatoes were cut in cubes with side 
of $15 \mathrm{~mm}$ and put on white plastic plates codified with a random three-digit code. Each container was closed with a plastic lid. Water was provided as palate cleanser at the start and between successive samples. The same preparation procedure was used in both sensory tests.

\section{Descriptive analysis}

Sensory profiles of eight potato samples were determined by the sensory panel of ASTRA laboratory (Imola, Italy). Test room was designed and managed following the ISO 8589:2007 (ISO 2007). The panel comprised eight trained judges (60\% females, aged $27-45$ years). The sensory panel was selected, trained and continuously monitored following the ISO 8586-1:2012 (ISO 2012). The panel evaluated the eight potato samples with an internally adapted procedure to establish a sensory profile developed following the ISO 13299:2016 (ISO 2016). The sensory profile approach is referred to in the text as descriptive analysis. A list of six attributes (two for tastes, one for flavour, and three for texture) was finally selected by the panel. Attributes, each of which was defined by a specific definition, were evaluated on nine-point scale (Table 1). For the purpose of tasting attribute, assessors were required to taste the sample, swallow and evaluate attributes for taste and flavour. Then, panellists were required to cut the sample with a knife to re-taste it and to evaluate texture properties. Samples were presented to panellists monadically and served in single-use, white plastic containers codified with a random three-digit code. A 1-min break was enforced between samples, when panellists rinsed their mouth with water. The descriptive analysis was conducted in two replicates. Each descriptive evaluation session lasted for approximately $1.5 \mathrm{~h}$.

\section{Triangle tests}

The triangle test approach was chosen to find any difference between samples without specifying the sensory characteristic(s) that differ. Triangle tests were performed following ISO 4120:2004 (ISO 2004). Four triangle tests were performed in total (12 samples). The evaluation session included two subsets, each comprising two triads. Each triad had three codified samples, two of which were identical, and one was the odd sample. Assessors must identify the odd sample. Within each triad, the comparison was between the biofortified sample and the correspondent control. Samples were served according to a randomised design $(\mathrm{ABB}, \mathrm{BAA}, \mathrm{AAB}, \mathrm{BBA}, \mathrm{ABA}$ and $\mathrm{BAB})$. A group of 46 subjects were involved ( $68 \%$ females, aged 24-50 years). Instructions required the assessors to taste the samples according to the provided order (from left to right), and to select the sample that they perceived as different from the other two within each triad. Assessors were asked to provide an answer even if they were not sure. Re-tasting was permitted. No time limitation was imposed on assessors. The presentation order of the triads was randomized across subjects. All evaluations were conducted between 12:00 noon and 2:00 pm.

\section{Chemical analysis}

\section{Reagents}

High purity grade solvents were used for iodine extraction. Tetramethylammonium hydroxide solution (TMAH, $1 \mathrm{M}$ ) was bought from Sigma Aldrich (St. Louis, $\mathrm{MO})$, and hydrogen peroxide solution $\left(\mathrm{H}_{2} \mathrm{O}_{2} 30 \% \mathrm{~m} / \mathrm{m}\right)$ was from Carlo Erba (Arese, MI, Italy). Ion exchange water (18 M $\Omega$ ) was obtained from Millipore Direct Q5 system (Millipore Co., Bedford, MA).

\section{lodine analysis}

Iodine analysis was performed on controls and treated potatoes at three different periods: immediately after harvest (T0), after three months (T3) and after six months of

Table 1. Sensory attributes and definitions used by the trained panel in descriptive analysis to describe iodine-biofortified potatoes and controls.

\begin{tabular}{|c|c|c|c|}
\hline $\begin{array}{l}\text { Sensory } \\
\text { modality }\end{array}$ & attribute & Definition & Scale \\
\hline \multirow[t]{2}{*}{ Taste } & Sweet & The perception of sweet taste on the tongue & $\begin{array}{l}1=\text { very low; } 5=\text { moderate; } \\
9=\text { very intense }\end{array}$ \\
\hline & Salty & The perception of salty taste on the tongue & $\begin{array}{l}1=\text { very low; } 5=\text { moderate; } \\
9=\text { very intense }\end{array}$ \\
\hline Flavour & Typical potato flavour & $\begin{array}{l}\text { The presence of an overall flavour typical for cooked potato } \\
\text { perceived after swallowing }\end{array}$ & $\begin{array}{l}1=\text { very low; } 5=\text { moderate; } \\
9=\text { very intense }\end{array}$ \\
\hline \multirow[t]{3}{*}{ Texture } & Hardness & $\begin{array}{l}\text { The resistance of flesh to knife cutting and mastication (to the } \\
\text { force impressed by teeth at the first bite) }\end{array}$ & $\begin{array}{l}1=\text { soft; } 5=\text { neither soft nor hard; } \\
9=\text { hard }\end{array}$ \\
\hline & Moistness & $\begin{array}{l}\text { The presence of liquid in the cut surface and perception of } \\
\text { suiciness in the mouth during mastication }\end{array}$ & $\begin{array}{l}1=\text { dry; } 5=\text { neither dry nor wet; } \\
9=\text { wet }\end{array}$ \\
\hline & Granulation & $\begin{array}{l}\text { The presence of granules with a certain dimension, perceived } \\
\text { during mastication }\end{array}$ & $\begin{array}{l}1=\text { coarse; } 5=\text { neither coarse nor } \\
\text { fine; } 9=\text { fine }\end{array}$ \\
\hline
\end{tabular}


storage (T6). T3 and T6 were measured only for a group of biofortified samples. A representative quantity of fresh potatoes was homogenised. About $0.5 \mathrm{~g}$ of sample was weighed directly in pyrex test tubes. Iodine was extracted by adding $6 \mathrm{~mL}$ of TMAH solution $(0.25 \mathrm{M})$ and $2 \mathrm{~mL}$ of $\mathrm{H}_{2} \mathrm{O}_{2}$ (30\%) followed by microwave mineralisation (Mars Express 5, CEM srl, Cologno al Serio, Italy). The extract was diluted with ultrapure water, centrifuged and filtered following the procedure previously developed (Comandini et al., 2013). Iodine content was determined with an inductively coupled plasma mass spectrometer (ICP-MS) (Agilent, Palo Alto, CA) using the following parameters: RF power $1550 \mathrm{~W}$, and argon flow rates of $1.05 \mathrm{~L} / \mathrm{min}$ and $0.2 \mathrm{~L} / \mathrm{min}$, respectively, for carrier gas and make-up gas. Instrument calibration was performed by employing iodine standards of up to a concentration of $100 \mathrm{mg} / \mathrm{L}$ in diluted TMAH solutions. Iodine analysis was done in triplicate.

\section{Statistical analysis}

The effect of samples on the perceived intensity of descriptors from panel was estimated using two-way mixed Analysis of Variance (ANOVA) models (random factor: judge; fixed factor: sample; model without interactions) separately conducted on each variable (sensory descriptor) considering eight products. All ANOVA models were followed by Tukey HSD test $(P<0.05)$. A Principal Component Analysis (PCA) was conducted on the mean intensity ratings of significant attributes obtained from a two-way mixed ANOVA, with the option of bootstrap hulls, which permitted to visualise the confidence areas of each sample. $T$-tests $(\mathrm{p}<0.05)$ were used to estimate Differences between the mean values obtained by the panel for both control samples and means obtained by the relative biofortified samples. For the triangle test, the following parameters were defined for 46 assessors: an $\alpha$-risk of 0.10 , a $\beta$-risk of 0.30 and a $p_{d}$ of 0.20 . The mean value of the three replicates was used for iodine analysis. Values of iodine are expressed in the text as mean and standard error of the mean for each storage time. A one-way ANOVA was conducted to estimate the effect of cultivar on the initial iodine content after harvesting among control samples (fixed factor: cultivar). The effect of iodine treatment within each cultivar was estimated after harvesting by four $t$-tests $(P<0.05)$, each comparing the content of iodine in the biofortified sample versus the related control sample. To assess the combined effect of the cultivar and the storage time on the final iodine content, a two-way fixed ANOVA was conducted (fixed factors: cultivar, and time of storage; model with interactions) considering 12 samples (four biofortified cultivars $\times$ three storage periods). Analyses were conducted with XLStat 2019.1.1 (Addinsoft, Boston, USA; package sensory).

\section{Results and Discussion}

\section{Sensory properties}

\section{Sensory profiles}

The sensory effects of addition of iodine to food have been described in previous papers (Greis et al., 2018; West and Koning, 1995). However, to the best of present authors' knowledge, this is the first study reporting on the systematic description (done with a trained panel) of the sensory profiles obtained from biofortified potatoes baked in an oven.

The two-way mixed ANOVA models indicated a significant effect of the sample $(P<0.05)$ for all attributes except for salty $(\mathrm{F}=2.04, P=0.06)$. Mean intensity values obtained from replicates of significant attributes were submitted for PCA. Two principal components were extracted, which accounted for $82.5 \%$ of the total data variance, with PC 1 accounting for 58.1\% and PC 2 for $24.4 \%$ variance (Figure $1 \mathrm{~A}$ ).

The first component (PC 1) was positively associated with two textural attributes: moistness and granularity, and sweetness, and negatively associated with the typical potato flavour. Granulation, moistness and sweetness were highly correlated to each other. The second component (PC 2) was positively associated with hardness, and negatively associated with granularity. The two Universa samples (Universa_B and Universa_C) were highly and positively associated with PC 1 , thereby showing a positive correlation with attributes having a positive loading on this component. Instead, Marabel (Marabel_B and Marabel_C), Cupido (Cupido_C and Cupido_B) and Orchestra_B samples had a negative correlation on PC 1 , thereby associated with a high intensity of typical potato flavour. However, Cupido_B, Cupido_C, Marabel_C, Orchestra_C and Universa_C had a negative score on PC 2. The bootstrap hulls plot showed samples with their confidence areas (Figure 1B). Some overlapping was observed in terms of perceptive properties, especially between Marabel_C and Cupido_B $B$ and between Cupido_C and Marabel_B, suggesting perceptive similarities between these two cultivars. Instead, Universa_B was clearly the most diverse sample which did not show perceptive overlaps with other samples.

The sensory profiles of the four cultivars comparing the control samples with the related biofortified samples at T6 are shown in Figure 2. Observed modifications in the sensory properties may have been induced by the iodine treatment in field, which was done in the last period of growth of tubers (about 2 weeks before harvest). In general, a few differences were found between controls and biofortified samples, and the sensory modifications observed from the $t$-test were small, similar to a recent 
(A)

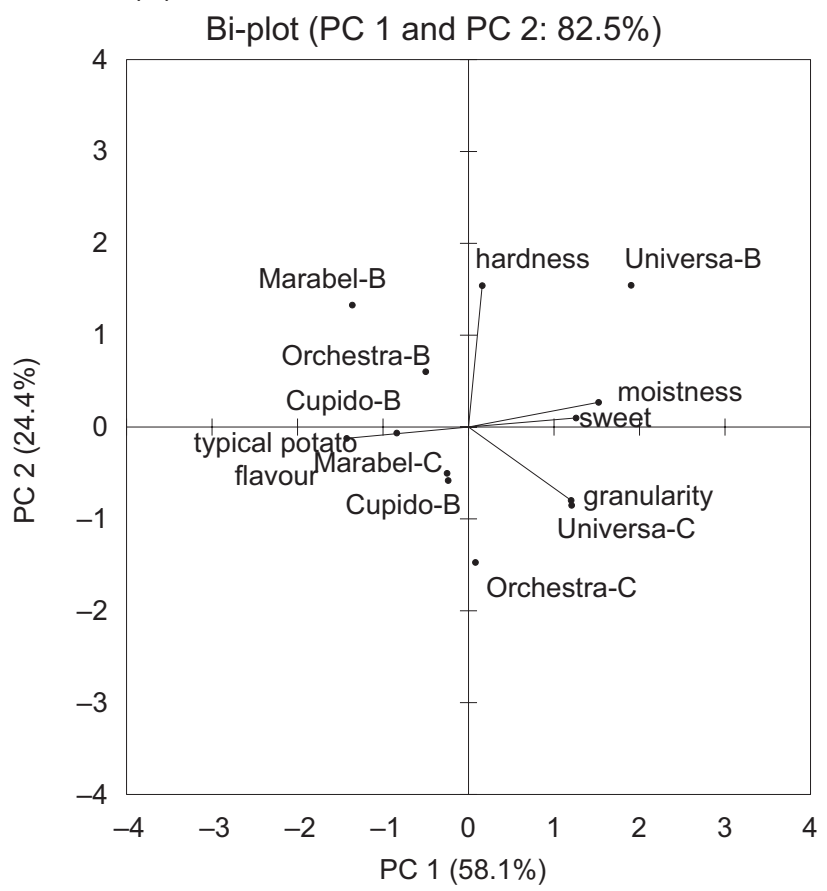

(B)

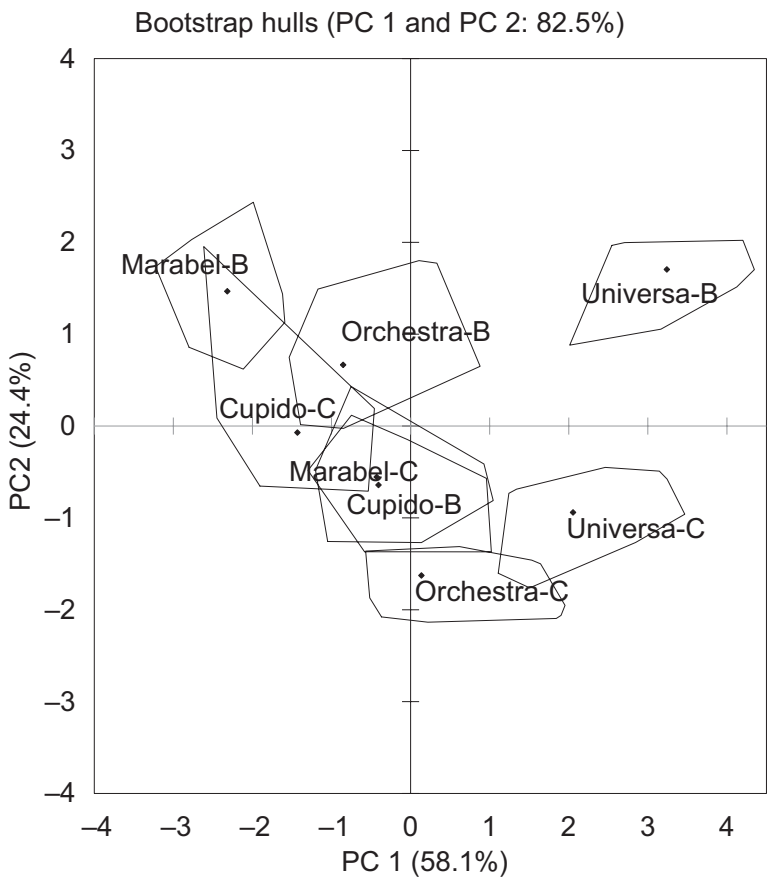

Figure 1. Bi-plot (1A) and bootstrap hulls plot (1B) from principal component analysis (PCA) of significant attributes used in descriptive analysis to describe eight samples of potatoes, including four controls (Cupido_C; Marabel_C; Orchestra_C; and Universa_C) and four biofortified samples (Cupido_B; Marabel_B; Orchestra_B; and Universa_B).

study which assessed the sensory modifications induced by addition of iodine in wheat bread, sausages and pickled cucumbers (Greis et al., 2018).

Cupido was the only cultivar that did not show any significant differences in the comparison of profiles (Figure 2A).

The typical potato flavour and sweetness were not affected by the treatment of iodine in any variety. The intensity of descriptor 'typical potato flavour' was in agreement with a previous study, showing that the addiction of salt containing 400-mg iodine from potassium iodide or iodate did not affect the flavour of boiled potatoes and boiled rice (West and Koning, 1995). Moreover, iodine content of up to $100 \mathrm{mg} / \mathrm{kg}$ did not affect the sensory attributes of pickle (Greis et al., 2018).

On the contrary, in the current study, the biofortification seems to influence the texture, with a general increase in the perceived hardness, which significantly increased in three out of four biofortified samples (Marabel, Orchestra and Universa).

The two other textural attributes (moistness and granularity) varied depending on the cultivar.

In Marabel, the biofortified sample (Marabel_B) showed a significant decrease $(P=0.03)$ in granularity and a significant increase in hardness $(P=0.02)$ (Figure 2B).
In biofortified Orchestra, the hardness significantly increased $(P \leq 0.01)$, while the perceived saltiness decreased $(P=0.03)$ (Figure $2 C)$. In biofortified Universa (Figure 2D), both hardness $(P \leq 0.001)$ and moistness $(P \leq$ $0.01)$ increased significantly.

In general, the texture of potatoes is determined by several mutually dependent factors (Jarén et al., 2016). The consistent increase in hardness found in the current study in biofortified samples may have been linked to the modification induced by the iodine within the starch structure. In fact, it is known that iodine may be bounded within the helical V-amylose component ( $\mathrm{Yu}$ et al., 1996), and this modification in the structure can translate into a microscopical increase in the perception of hardness. A few existing studies on the effect of iodine on texture seems inconsistent across different food products. Greis and colleagues (2018) found the largest deviation from the reference for tenderness for sausages but no difference in hardness for iodized and non-iodized pickles. Meat samples (sausages) containing a high quantity of iodine were tenderer (Greis et al., 2018), probably because of the variation in their water-holding capacity (WHC). Iodate appeared to soften vegetable pickles in brine during storage (12 days) (Amr and Jabay, 2004), which goes opposite to our results. Taken together, these results suggest that a few sensory modifications induced by the iodine biofortification strongly depend on the type of food matrix used. 


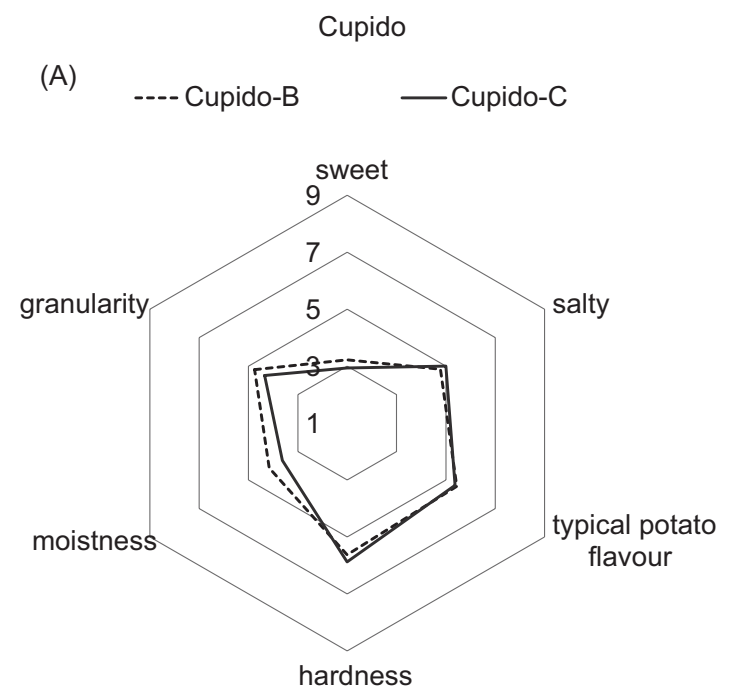

(C)

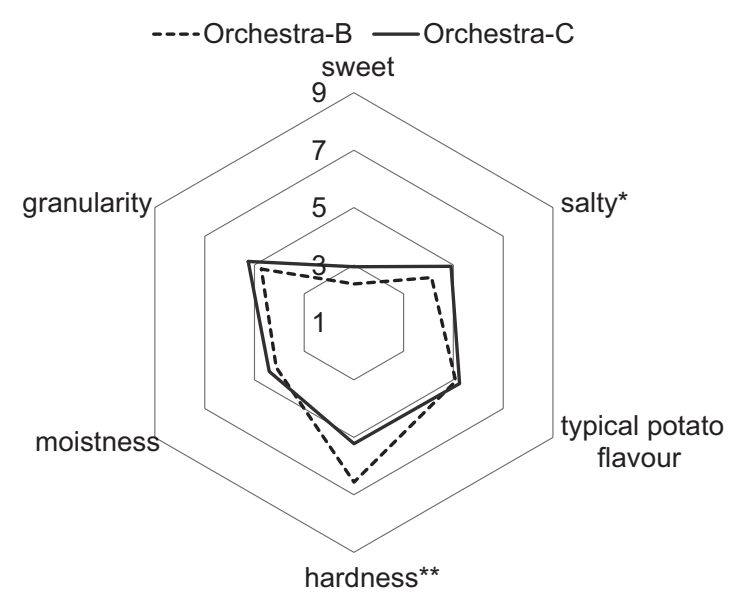

(B)

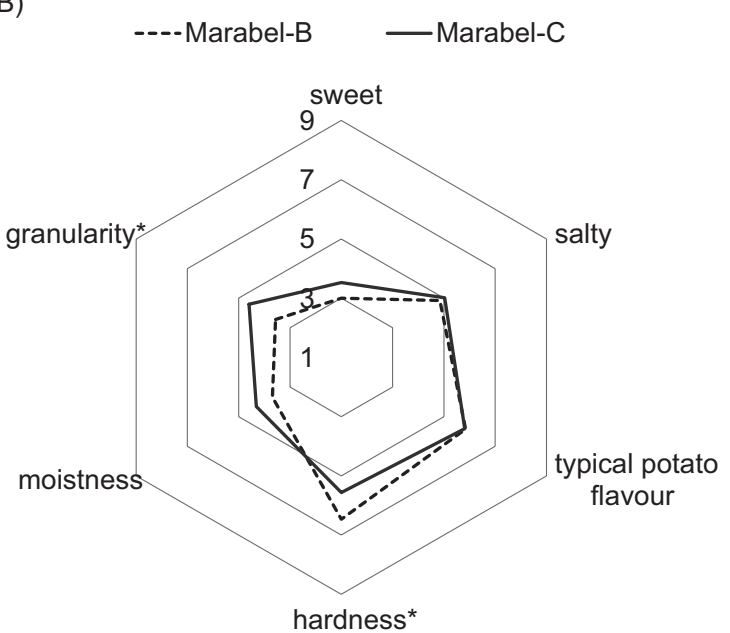

(D)

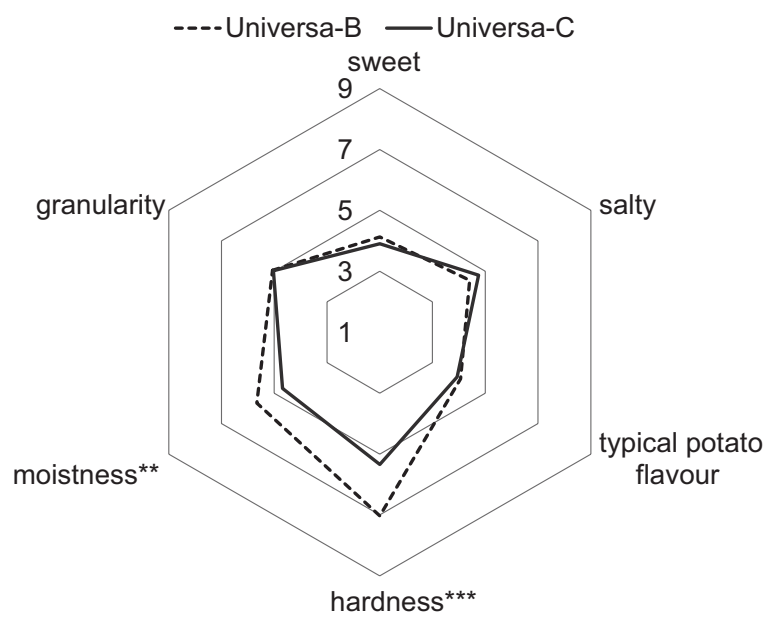

Figure 2. Sensory profiles of the control samples (continuous lines) and biofortified samples (dashed lines) for the cultivars: (A) Cupido, (B) Marabel, (C) Orchestra and (D) Universa. Asterisks indicate significant different mean values from t-tests for the considered attribute $\left({ }^{*} P \leq 0.05,{ }^{* *} P \leq 0.01,{ }^{* * *} P \leq 0.001\right)$.

\section{Overall sensory difference}

Results of triangle tests for the four cultivars are shown in Table 2.

No significantly perceivable differences were found between any control sample and its respective biofortified sample at $\mathrm{T} 6$, thus indicating that the biofortification was not perceived in the population of subjects. The fact that no significant differences were found from triangle tests between treated samples and control samples suggested that differences found from descriptive analysis were minor, and therefore it was unlike that naive consumers may have noticed them. The two sensory techniques gave some slightly different outputs because descriptive analysis was conducted by trained assessors, while triangle tests with naive consumers. Apart from the different expertise of the two groups, the approach was fully different. Triangle test is an overall difference test (Meilgaard et al., 2007b), while descriptive analysis is an approach that requires an analytical evaluation of each descriptor (Meilgaard et al., 2007a).

\section{lodine content and stability}

Table 3 shows the iodine content after harvest (T0) in controls, and that in biofortified cultivars at three storage periods (T0, T3 and T6). The amount of iodine present in control samples (not treated) was derived from the environment elements (soil, water and air) 
Table 2. Results of triangle tests conducted at T6 to estimate significant differences between biofortified samples and their respective controls. Each row shows the results of each cultivar from comparison between the biofortified samples and the relative control samples.

\begin{tabular}{lccccc} 
Cultivar & Assessors (N) & Critical number of correct responses & Correct responses given $(\mathbf{n})$ & $\mathbf{p}_{\mathrm{d}}$ & $\boldsymbol{P}_{\text {-value }}$ \\
\hline Cupido & 44 & 20 & 18 & 0.11 & 0.18 \\
Marabel & 44 & 20 & 19 & 0.15 & 0.11 \\
Orchestra & 47 & 21 & 20 & 0.14 & 0.12 \\
Universa & 46 & 20 & 17 & 0.05 & 0.35 \\
\hline
\end{tabular}

Note: $p_{d}$ is the maximum proportion of assessors being able to detect a difference between products.

Table 3. lodine content ( $\mu \mathrm{g} / 100 \mathrm{~g}$ ) in controls ('C') and relative iodine-biofortified samples ('B') at three different periods of storage (after harvesting $=\mathrm{T} 0$, after three months $=\mathrm{T} 3$ and after six months of storage $=\mathrm{T} 6$ ).

\begin{tabular}{|c|c|c|c|c|}
\hline \multirow[t]{2}{*}{ Cultivar } & \multirow[t]{2}{*}{ Samples } & \multicolumn{3}{|c|}{ Storage time } \\
\hline & & TO* & T3 & T6 \\
\hline \multirow[t]{2}{*}{ Cupido } & Cupido_C & $2.2 \pm 0.3$ & & \\
\hline & Cupido_B & $40.1 \pm 3.9^{a, b, c, d \star d x}$ & $36.4 \pm 3.9^{a, b, c, c, d}$ & $37.0 \pm 3.9^{a, b, c, d}$ \\
\hline \multirow[t]{2}{*}{ Marabel } & Marabel_C & $3.2 \pm 0.3$ & & \\
\hline & Marabel_B & $32.1 \pm 3.9^{b, c, d, e^{*}}$ & $24.5 \pm 3.9^{c, d, e}$ & $22.9 \pm 3.9^{c, d, e}$ \\
\hline \multirow[t]{2}{*}{ Orchesta } & Orchestra_C & $6.7 \pm 0.3$ & & \\
\hline & Orchestra_B & $52.4 \pm 3.9^{a^{*}}$ & $42.4 \pm 3.9^{\mathrm{a} a \mathrm{~b}, \mathrm{c}}$ & $48.7 \pm 3.9^{a, b}$ \\
\hline \multirow[t]{2}{*}{ Universa } & Universa_C & $2.8 \pm 0.3$ & & \\
\hline & Universa_B & $23.7 \pm 3.9^{c, d, e^{*}}$ & $20.9 \pm 3.9^{d, e}$ & $15.7 \pm 3.9^{e}$ \\
\hline
\end{tabular}

Values are mean \pm standard error of three measurements.

*Mean values of biofortified samples significantly differ from mean values of respective control samples at T0 from $t$-test $(P \leq 0.01)$.

Different letters in mean values across the 12 biofortified samples indicate significantly different iodine contents from two-way ANOVA followed by

Tuckey's HSD test $(P<0.05)$.

(Osterc et al., 2011). At T0, Orchestra_C had the significantly highest iodine content $(6.7 \pm 0.3 \mu \mathrm{g} / 100 \mathrm{~g}) \mathrm{com}$ pared to the other control samples, suggesting that this cultivar is naturally richer in iodine.

In general, standard errors associated with the iodine analysis were high. This was because the sample preparative phase of this method (extraction) suffers from an intrinsic variability of sub-samples (replicates) that can greatly vary despite a proper homogenisation of the matrix (e.g. for the water content of single tuber, for different accumulations of micro- and macro-components in tuber etc.), thus resulting in high variations in standard errors.

As expected, $t$-test confirmed that the iodine content significantly $(P \leq 0.01)$ and strongly increased in all biofortified samples, independent of the initial iodine content (Table 3). This suggests that the agronomic treatment was effective in fresh potatoes, confirming results of other authors ( Caffagni et al., 2011, 2012; Zanirato and Mayerle, 2009).
The four cultivars showed different accumulation efficiencies in agreement with a previous study, which observed that the accumulation efficiency varied not only across potatoes (Caffagni et al., 2012) but also for different amounts of iodine provided (Caffagni et al., 2011). The increased ratio (the ratio of amount of iodine in biofortified and control samples) was approximately 18 (for Cupido), 10 (for Marabel) and 8 times more (for Orchestra and Universa). Therefore, Cupido showed the highest increased ratio. These differences in accumulation efficiency across varieties could be derived from different responses of cultivars to iodine treatment. Since the iodine behaviour in a soil-plant system is very complex due to the high number of factors involved (Fuge and Johnson, 2015), different varieties of plants absorb iodine differently.

The two-way ANOVA showed a significant strong effect of the biofortified cultivar $(\mathrm{F}=23.352, P<0.001)$ on the final iodine content but no effect of the storage time $(\mathrm{F}=3.088, P=0.064)$ nor of the interaction of cultivar and storage time (cultivar $\times$ storage time; $\mathrm{F}=0.471, P=$ 0.823) (data not shown). The lack of effect of storage 
time indicated that the content of iodine is substantially stabile during the considered time, in agreement with a previous study (Caffagni et al., 2012), which noted no significant effect of storage time on iodine content in potato tubers. The lack of effect of interaction (cultivar $\times$ storage time) indicated similar trends in iodine contents over time across the considered cultivars.

Instead, the strong effect of cultivar indicated a difference in the total iodine amount across the biofortified cultivars, as shown in Table 3. After six months of storage, among the biofortified samples, Orchestra_B had significantly the highest amount of iodine $(48.7 \pm 3.9 \mu \mathrm{g} / 100$ g), not significantly different from Cupido_B (37.0 \pm 3.9 $\mu \mathrm{g} / 100 \mathrm{~g})$, followed by Marabel_B $(22.9 \pm 3.9 \mu \mathrm{g} / 100 \mathrm{~g})$ and Universa_B $(15.7 \pm 3.9 \mu \mathrm{g} / 100 \mathrm{~g})$, which did not differ significantly from each other. Orchestra cultivar seemed to be the most suited variety for iodine biofortification, while Universa cultivar is the least suited because of its lowest accumulation efficiency (according to the iodine increased ratio after treatment) and the lowest final content of iodine after six months.

\section{Conclusions}

On the one hand, the data obtained from the present work confirmed the effectiveness of the agronomical practice of iodine biofortification in potatoes. Iodine content was stable for six months under the conventional storage conditions in all cultivars. On the other hand, this study extended the knowledge by providing a systematic description of the sensory effects of iodine-biofortified potatoes, considering four different potato cultivars (Cupido, Marabel, Orchestra and Universa).

The descriptive analysis highlighted a few differences between biofortified and control samples, mainly in texture (hardness), probably because of modifications in the starch structure of potatoes induced by iodine. However, differences were small and were not detected by consumers in triangle tests. Therefore, iodine biofortification seems to be a suitable and promising technique for potatoes, since it does not compromise the sensory properties and it allows to develop functional vegetables (that is products with improved nutritional characteristics), which could be successful by consumers. A further development of the study could be the exploration of consumers' perception related to liking of biofortified samples, targeting specific consumers (e.g. consumers with specific nutritional needs).

\section{Acknowledgement}

The authors gratefully acknowledge the Pizzoli S.p.A. Company (Budrio, Italy) for useful collaboration and for kindly donating potato samples and the ASTRA laboratory (Faenza, Italy).

\section{Author Contributions}

All authors contributed to the study's conception and design. M. Piochi undertook the analyses and wrote the paper. All authors critically contributed and commented on the previous versions of the manuscript. All authors read and approved the final manuscript.

\section{Compliance with Ethical Standards}

The research was conducted on human volunteers, and it was in conformity with the Declaration of Helsinki. Written informed consent was obtained from all participants before inclusion in the sensory tests.

\section{Conflict of Interest}

The authors declare that they have no conflict of interest. Vegetables were supplied free of charge with no obligation between researchers and suppliers.

\section{References}

Amr, A. and Jabay, Omar A. 2004. Effect of salt iodization on the quality of pickle vegetable. Food, Agriculture \& Environment, 2(2), pp. 151-156. https://doi.org/10.1234/4.2004.184.

Caffagni, A., Arru, L., Meriggi, P., Milc, J., Perata, P. and Pecchioni, N. 2011. Iodine fortification plant screening process and accumulation in tomato fruits and potato tubers. Communications in Soil Science and Plant Analysis 42(6):706-718. https://doi.org/10.10 80/00103624.2011.550372.

Caffagni, A., Pecchioni, N., Meriggi, P., Bucci, V., Sabatini, E., Acciarri, N., Ciriaci, T. et al. 2012. Iodine uptake and distribution in horticultural and fruit tree species. Italian Journal of Agronomy 7(3):229-236. https://doi.org/10.4081/ija.2012.e32.

Carvalho, Susana M.P. and Vasconcelos, Marta W. 2013. Producing more with less: strategies and novel technologies for plant-based food biofortification. Food Research International 54(1):961971. https://doi.org/10.1016/j.foodres.2012.12.021.

Comandini, P., Cerretani, L., Rinaldi, M., Cichelli, A. and Chiavaro, E. 2013. Stability of Iodine during cooking: investigation on biofortified and not fortified vegetables. International Journal of Food Sciences and Nutrition 64(7):857-861. https:// doi.org/10.3109/09637486.2013.798270.

Dal Bello, B., Torri, L., Piochi, M., Bertolino, M. and Zeppa, G. 2017. Fresh cheese as a vehicle for polyunsaturated fatty acids integration: effect on physico-chemical, microbiological and sensory characteristics. International Journal of Food Sciences and Nutrition 68(7):800-810. https://doi.org/10.1080/09637486.2017.1301891. 
Dwyer, Johanna T, Wiemer, K.L., Dary, O., Keen, C.L., King, Janet C., Miller, Kevin B., Philbert, Martin A et al. 2015. Fortification and health: challenges and opportunities. Advances in Nutrition 6(1):124-131. https://doi.org/10.3945/an.114.007443.

Fuge, R. and Johnson, C. C. 2015. Iodine and human health, the role of environmental geochemistry and diet, a review. Applied Geochemistry 63:282-302. https://doi.org/10.1016/j. apgeochem.2015.09.013.

Gonzali, S., Kiferle, C. and Perata, P. 2017. Iodine biofortification of crops: agronomic biofortification, metabolic engineering and iodine bioavailability. Current Opinion in Biotechnology 44:16-26. https://doi.org/10.1016/j.copbio.2016.10.004.

Greis, M., Seppä, L., Venäläinen, E.R., Lyytikäinen, A. and Tuorila, H. 2018. LWT-food science and technology impact of iodized table salt on the sensory characteristics of bread, sausage and pickle. LWT 93(2017, November):606-612. https://doi. org/10.1016/j.lwt.2018.04.009.

Hotz, C. 2013. Biofortification Editor: Benjamin Caballero. In: Encyclopedia of human nutrition, third edition, Editor-inChief: Benjamin Caballero. Elsevier, pp. 175-181. https://doi. org/10.1016/B978-0-12-375083-9.00025-8

International Organization for Standardization (ISO). 2004. Sensory analysis-methodology-triangle Test. ISO 4120:2004.

International Organization for Standardization (ISO). 2007. General guidance for the design of test rooms. ISO 8589:2007.

International Organization for Standardization (ISO). 2012. Training and monitoring of selected assessors and expert sensory assessors. ISO 8586:2012 selection.

International Organization for Standardization (ISO). 2016. Sensory analysis methodology: general guidance for establishing a sensory profile. ISO 13299:2016, p. 41.

Jarén, C., López, A. and Arazuri, S. 2016. Advanced analytical techniques for quality evaluation of potato and its products. advances in potato chemistry and technology, 2nd ed. Elsevier, Cambridge, MA. https://doi.org/10.1016/B978-0-12-800002-1.00019-4.

Khattak, R.M., Khattak, M.N.K., Ittermann, T. and Völzke, H. 2017. Factors affecting sustainable iodine deficiency elimination in Pakistan: a global perspective. Journal of Epidemiology 27(6):249-257. https://doi.org/10.1016/j.je.2016.04.003.

Meilgaard, MC, Civille, G.V. and Carr, B.T. 2007a. Descriptive analysis technique. In Sensory evaluation techniques, 4th ed. CRC Press, Boca Raton, FL, pp. 173-88. https://doi.org/10.2320/ materia.46.171.

Meilgaard, MC, Civille, G.V. and Carr, B.T. 2007b. Overall difference tests: does a sensory difference exist between samples? In Sensory evaluation techniques, 4th ed. CRC Press, Boca Raton, FL, pp. 63-104. https://doi.org/10.1201/b16452-7

Osterc, A., Stibilj, V. and Raspor, P. 2011. Iodine in the environment. In Encyclopedia of environmental health, Editor-in-Chief: J.O. Nriagu. Elsevier B.V. pp. 280-287. https://doi.org/10.1016/ B978-0-444-52272-6.00705-4.
Saltzman, A, Birol, E., Bouis, Howarth E., Boy, E., De Moura, Fabiana F., Islam, Y. and Pfeiffer, Wolfgang H. 2013. Biofortification: progress toward a more nourishing future. Global Food Security 2(1):9-17. https://doi.org/10.1016/j. gfs.2012.12.003.

Smoleń, S., Kowalska, I. and Sady, W. 2014. Assessment of biofortification with iodine and selenium of lettuce cultivated in the NFT hydroponic system. Scientia Horticulturae 166:9-16. https:// doi.org/10.1016/j.scienta.2013.11.011.

Tonacchera, M., Dimida, A., Servi, M. De, Frigeri, M., Ferrarini, E., Marco, G. De, Grasso, L. et al. 2013. Iodine fortification of vegetables improves human iodine nutrition: in vivo evidence for a new model of iodine prophylaxis. Journal of Clinical Endocrinology and Metabolism 98(4):694-697. https://doi. org/10.1210/jc.2012-3509.

Torri, L., Piochi, M., Marchiani, R., Zeppa, G., Dinnella, C. and Monteleone, E. 2016. A sensory- and consumer-based approach to optimize cheese enrichment with grape skin powders. Journal of Dairy Science 99(1):194-204. https://doi.org/10.3168/ jds.2015-9922.

Trumpff, C., Schepper, J. De, Tafforeau, J., Oyen, H.V., Vanderfaeillie, J. and Vandevijvere, S. 2013. Mild iodine deficiency in pregnancy in Europe and its consequences for cognitive and psychomotor development of children: a review. Journal of Trace Elements in Medicine and Biology 27(3):174-183. https://doi.org/10.1016/j.jtemb.2013.01.002.

Verbeke, W. 2006. Functional foods: consumer willingness to compromise on taste for health? Food Quality and Preference 17(12):126-131. https://doi.org/10.1016/j.foodqual.2005.03.003.

Weng, H. X., Hong, C.L., Xia, T.H., Bao, L.T., Liu, H.P. and Li, D.W. 2013. Iodine biofortification of vegetable plants-an innovative method for iodine supplementation. Chinese Science Bulletin 58(17):2066-2072. https://doi.org/10.1007/s11434-013-5709-2.

West, C. E and Koning, F.L.H.A. De. 1995. Effect of iodized salt on the colour and taste of food. New York: United Nations Children's Fund, report under contract No. PD/95/009.

Winger, R.J., König, J., and House, Don A. 2008. Technological issues associated with iodine fortification of foods. Trends in Food Science \& Technology, 19(2), 94-101. https://doi.org/10.1016/j. tifs.2007.08.002.

Yu, X., Houtman, C. and Atalla, R.H. 1996. The complex of amylose and iodine. Carbohydrate Research 292:129-141. https://doi. org/10.1016/0008-6215(96)00159-0.

Zanirato, V. and Mayerle, M. 2009. Method for enriching crops with iodine, and crops thus obtained. European patent specification No. EP 2234471 B1, issued 2009. https://doi.org/10.1385/ BTER.

Zimmermann, Michael B. and Andersson, M. 2012. Assessment of iodine nutrition in populations: past, present, and future. Nutrition Reviews 70(10):553-570. https://doi. org/10.1111/j.1753-4887.2012.00528.x. 